\title{
Design of Net Energy Metering System for a Hybrid Energy Storage System
}

\author{
Chandragiri Radha Charan, Palla Tejaswini
}

\begin{abstract}
The expectation for everyday comforts and success of a country fluctuate legitimately with the expansion in the utilization of intensity. The power necessity of the world is expanding at a disturbing rate because of mechanical development, expanded and broad utilization of electrical device. As per world vitality report, around $80 \%$ of our vitality is received from regular non-renewable energy sources like oil, gaseous petrol and coal. It is evident from the current scenario that world will have to face the shortage of resources within no time. Hence, it is a call for an alternative vitality source search and there are many such attempts in recent times. The best elective source is sun powered vitality. This targets in structuring a hybrid Energy Storage System with Net Metering billing methodology to make the client profit from Variable Rate Electricity. Net energy metering system is an uncommon charging game plan that furnishes acknowledge to clients for sun powered $P V$ frameworks for the full retail estimation of the power their framework creates. Under NEM, client's electric meter monitors how much power is devoured by the client and how much abundance power is produced by the framework and sent go into the electric utility lattice.
\end{abstract}

Keywords: Energy storage systems [ESS], net energy metering [NEM], time-of-use [TOU], Vitality.

\section{INTRODUCTION}

Vitality is one of the significant contributions for the monetary economical improvement of any nation. On account of the creating nations, the energy part expect a basic significance in perspective on the regularly expanding vitality needs requiring gigantic ventures to meet them, Regular essential vitality sources are coal, oil, gas, and biomass. Other imperativeness sources accessible incorporate atomic vitality from radioactive substances, warm vitality put away in inside of the earth, and potential vitality because of gravity of earth [1]. Sustainable power source is the energy derived from sources that are basically limitless. Instances of inexhaustible assets incorporate breeze power, sun based force, geothermal energy, tidal force and hydroelectric force. The most significant element of

Revised Manuscript Received on February 05, 2020.

* Correspondence Author

C. Radha Charan*, Assistant Professor, Department of Electrical \& Electronics Engineering, JNTUH College of Engineering, Jagtial, T.S., India. e-mail: crcharan@jntuh.ac.in

Ms. P. Tejaswini, Pursuing M.Tech., Department of Electrical Power Systems, JNTUH College of Engineering, Jagtial, T.S., India. E-mail:tejaswini.palla07@gmail.com

(C) The Authors. Published by Blue Eyes Intelligence Engineering and Sciences Publication (BEIESP). This is an open access article under the CC BY-NC-ND license (http://creativecommons.org/licenses/by-nc-nd/4.0/) sustainable power source is that it tends to be bridled without the arrival of harmful contamination. Hence, the developing countries these days are into the utilization of sustainable or renewable energy sources for its energy requirements [3]. Part of it, this is to use multiple types of renewable energy sources simultaneously in order to avail the maximum benefit. Here, three energy sources say solar, wind and tidal as the three type of sources in action. To such a system including three different energy sources acting simultaneously, an uncommon billing system [4] is designed when the system [2] is connected to the utility grid. The design of such a billing system is based on a methodology of taking the net energy into count and the time of use into count not the peak or base values. Hence this is mainly to design a hybrid energy storage system with a special billing setup named Net Energy Metering system [5].

\section{BLOCK DIAGRAM OF THE SYSTEM}

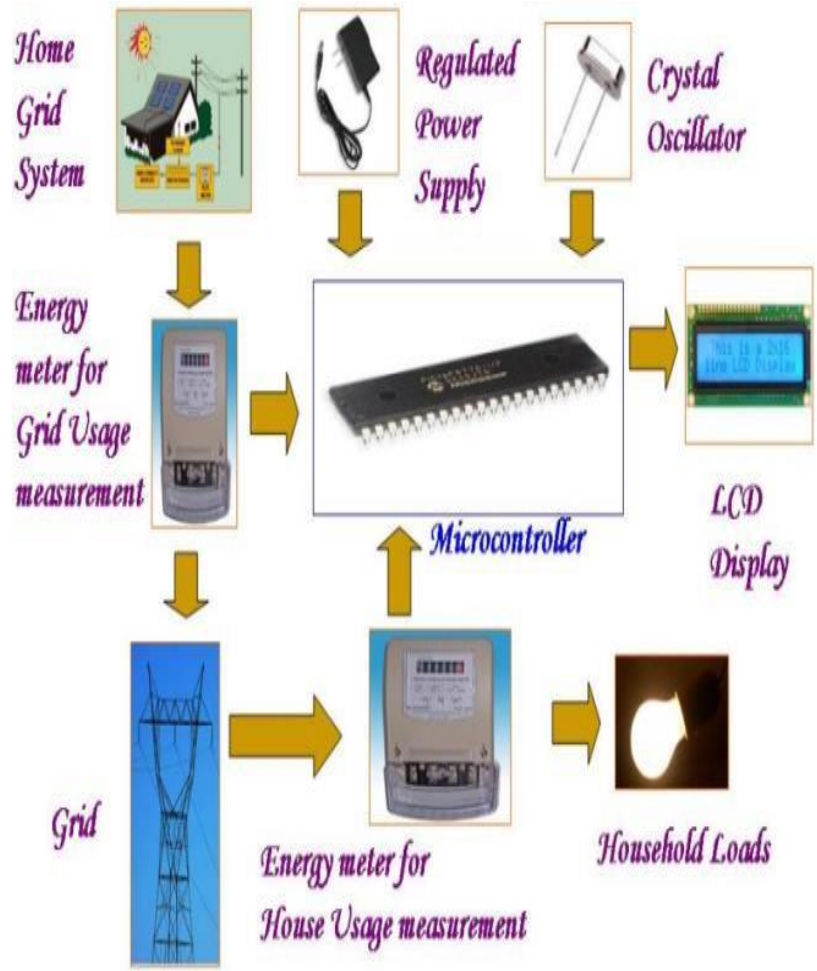

Fig. 1. Block diagram of net energy metering system with hybrid energy storage system

The above system is precisely designed to achieve the following two:

1. Intelligent power sharing system with electricity grid.

2. Net billing on LCD after deducting energy given to the grid. 


\section{Design of Net Energy Metering System for a Hybrid Energy Storage System}

The major building blocks of the design are Solar panel, Charge Controller Energy Meters, Crystal oscillator, Home grid system, LCD with drive. The system consists of two input blocks. One is the Energy Meter getting operated through Inverter which in turn gets operated through the energy from the Solar Panel. The customer gives this electricity to the utility. This amount of electricity will be billed by the Microcontroller with the help of Energy Meter Reading. The other input block is the Energy Meter from the normal Mains supply through which the Microcontroller calculates the number of units the user has used and does the billing work. The Microcontroller now displays the Net amount to be paid by the customer i.e., the net amount of electricity the customer exported to the utility subtracted from the net amount of electricity the customer has consumed during that billing period. The net amount is displayed on LCD. The three energy sources say solar, wind and tidal are privately connected to battery through charging circuit as in fig 4.and the charging circuit is as shown in fig 2.

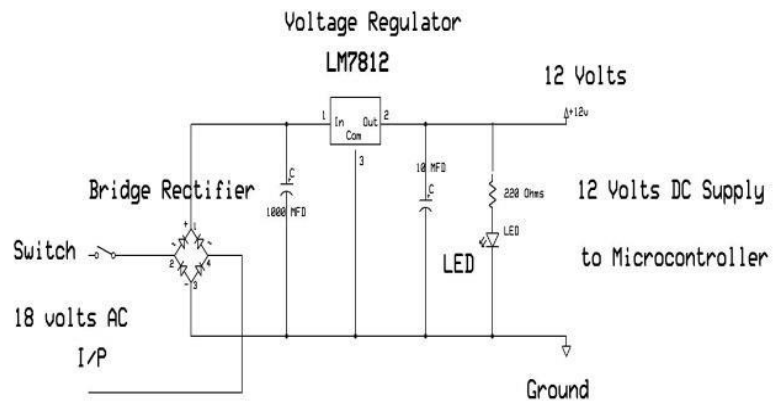

Fig. 2. Charging circuit

The interfacing of the microcontroller with the LCD display as well as energy meters is shown fig. 3 .

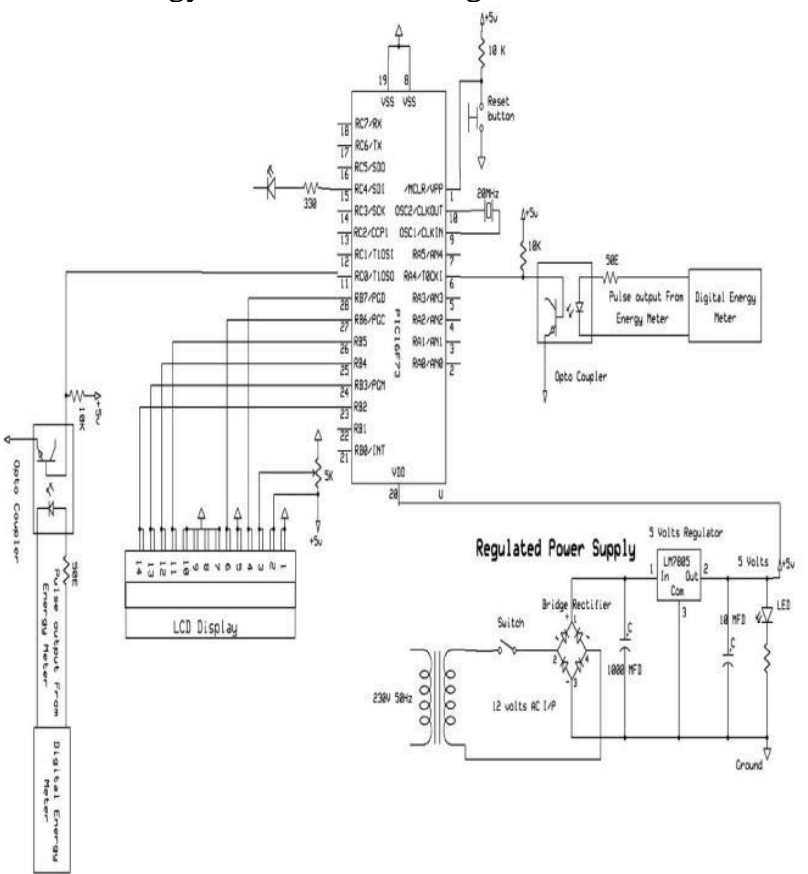

Fig. 3. Schematic diagram of interfacing PIC16F73 microcontroller with energy meter and LCD display

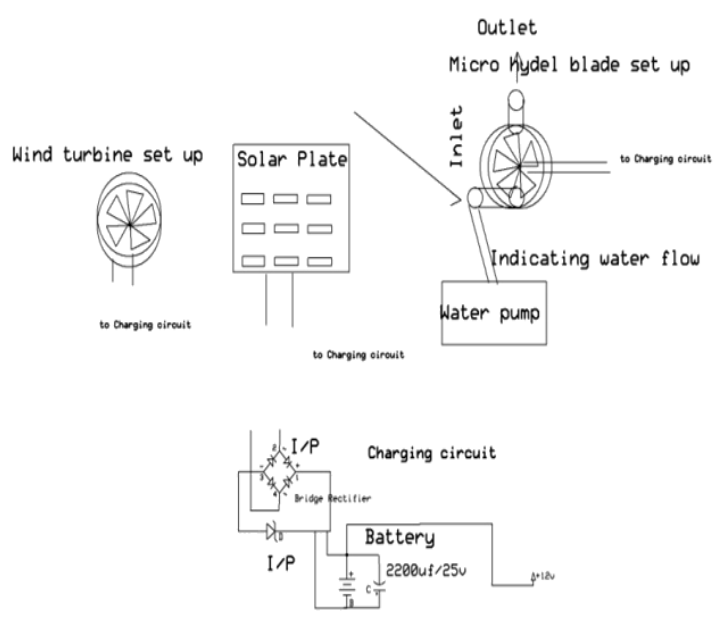

Fig. 4.Schematic diagram of solar, wind and tidal energy sources connected to battery through charging circuit

\section{EXPERIMENTAL RESULTS}

The fig. 5 below shows the LCD displaying the initial condition i.e. Designing of Net metering system as soon as the net energy metering unit is ON.

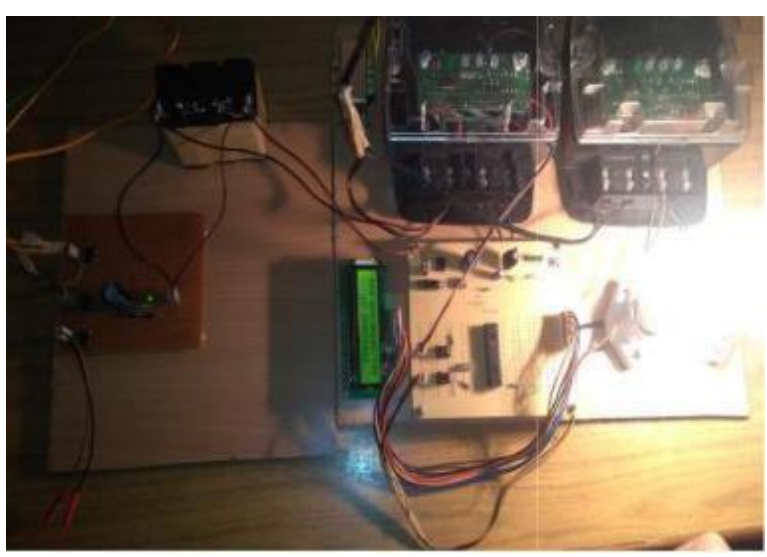

Fig. 5.LCD displaying the initial condition

The fig. 6 shown below explains the energy utilized for home loads and energy given to utility displayed by LCD.

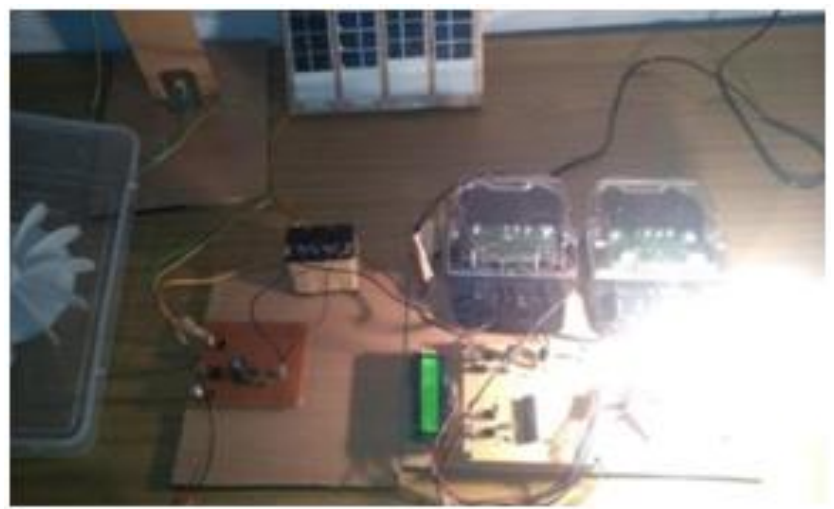

Fig. 6.LCD displaying the energy utilized for home loads (indicated as HOME) and energy given to utility grid (indicated as GOVT)

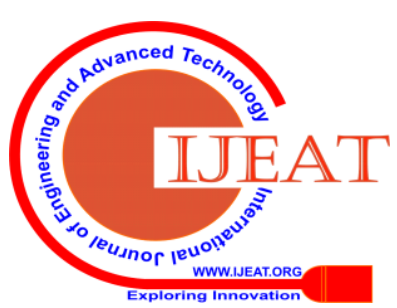


The below fig. 7 explains the net energy calculated by the microcontroller and also by whom the amount to be paid either by government to consumer or vice versa by Government pay units or consumer pay units.

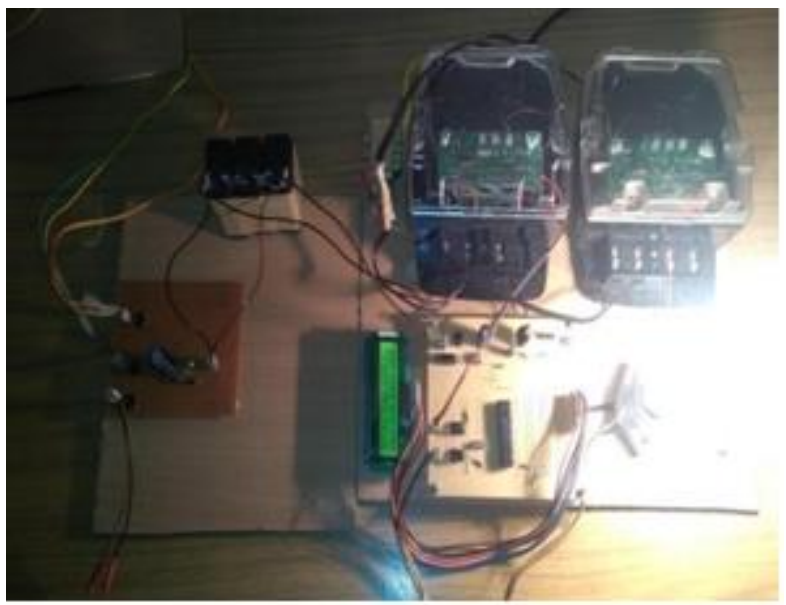

Fig. 7.LCD displaying the net energy

The details mentioned in the below table- 1 indicates the amount of energies provided to the home grid as well as to utility grid which results in the calculation of the net energy indicated by -sign in the above case explaining us the utility grid is in debt to home grid.

Table-1: Experimental model

\begin{tabular}{|c|c|c|c|c|}
\hline $\begin{array}{c}\text { Sl. } \\
\text { No }\end{array}$ & $\begin{array}{l}\text { HOME } \\
\text { GRID }\end{array}$ & $\begin{array}{c}\text { UTILITY } \\
\text { GRID }\end{array}$ & $\begin{array}{c}\text { NET } \\
\text { ENERGY }\end{array}$ & $\begin{array}{c}\text { PAYMENT } \\
\text { CONDITION }\end{array}$ \\
\hline 1 & 0.003 & 0.006 & -0.0021 & $\begin{array}{c}\text { Utility to } \\
\text { home }\end{array}$ \\
\hline
\end{tabular}

\section{APPLICATIONS}

This system can be practically implemented in real time in industries and domestic houses.

1.House electrical systems.

2.Railway electrical systems.

3.Remote controlling systems.

4.Phone Billing systems.

\section{CONCLUSION}

Incorporating highlights of all the equipment segments utilized have been created in it. Nearness of each module has been contemplated out and put cautiously, along these lines adding to the best working of the unit. Also, utilizing exceptionally propelled IC's with the assistance of developing innovation, the undertaking has been effectively actualized. In this manner the task has been effectively planned and tried. Under NEM, the client's electric meter monitors how much power is devoured by the client and how much abundance power is produced by the framework and sent go into the electric utility lattice. The advantages of employing these special billing methodologies have been checked on. The outcomes show vitality stockpiling can essentially decrease power cost by top shaving and burden moving for the business client and by putting away abundance sustainable power source for the private client. The affectability of yearly power cost to ESS's sizes is additionally examined. Future work around there would consider the vulnerabilities of estimate blunders just as incorporate a non-straight vitality stock piling model.

\section{REFERENCES}

1. D. Manz, R. Walling, N. Miller, B. LaRose, R. D'Aquila, and B. Daryanian, "The grid of the future: Ten trends that will shape the grid over the next decade," IEEE Power and EnergyMagazine, vol. 12, no. 3, pp. 26-36, May 2014.

2. J. Eyer and G. Corey, "Energy storage for the electricity grid: Benefits and market potential assessment guide," Sandia National Laboratories, Albuquerque, NM, SAND2010-0815, Tech. Rep., Feb 2010.

3. X. Luo, J. Wang, M. Dooner, and J. Clarke, "Overview of current development in electrical energy storage technologies and the application potential in power system operation," Applied Energy, vol. 137, pp. 511 - 536, 2015.

4. Analytic challenges to valuing energy storage. [Online]. Available: https://goo.gl/V4i0Ka.

5. Y.J. Zhang, C. Zhao, W. Tang, and S.H. Low, "Profit maximizing planning and control of battery energy storage systems for primary frequency control," IEEE Transactions on Smart Grid, vol. PP, no. 99, pp. 1-12, 2016.

6. R.H. Byrne and C.A. Silva-Monroy, "Estimating the maximum potential revenue for grid connected electricity storage: Arbitrage and the regulation market," Sandia National Laboratories, Albuquerque, NM, SAND2012-3863, resreport, 2012.

7. R.H. Byrne and C.A. Silva-Monroy, "Potential revenue from electrical energy storage in ercot: The impact of location and recent trends," in 2015 IEEE Power Energy Society GeneralMeeting, July 2015, pp. 1-5.

8. R.H. Byrne, R.J. Conception, and C.A. Silva-Monroy, "Estimating potential revenue from electrical energy storage in pjm," 2016 IEEE Power Energy Society General Meeting, July 2016,pp. 1-5.

9. T.A. Nguyen, R.H. Byrne, R.J. Conception, and I. Gyuk, "Maximizing revenue from electrical energy storage in miso energy \& frequency regulation markets," in 2017 IEEE Power Energy Society General Meeting, July 2017.

10. H. Khani, M. Zadeh, and A.H. Hajimiragha, "Transmission congestion relief using privately owned large-scale energy storage systems in a competitive electricity market," IEEE Transactions on Power Systems, vol. 31, no. 2, pp. 1449-1458,March 2016.

\section{AUTHORS PROFILE}

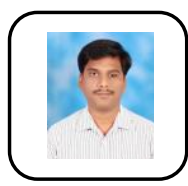

C. Radha Charan, currently working as an Assistan Professor , Department of Electrical \& Electronics Engineering , JNTUH College of Engineering, Jagtial, T.S., India.

E-mail: crcharan@jntuh.ac.in

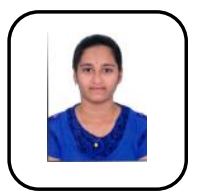

Ms. P. Tejaswini, received the B.Tech. degree in Electrical and Electronics Engineering from Jawaharlal Nehru Technological University, Hyderabad, India, in 2018. Currently pursuing M.Tech. in Electrical Power Systems in JNTUH College of Engineering, Jagtial, T.S., India. E-mail:tejaswini.palla07@gmail.com 